\title{
DFT Study on Electronic Interactions of Pt, Pd and Au Atoms with $\gamma-\mathrm{Al}_{2} \mathrm{O}_{3}$
}

\author{
Han WEI ${ }^{1}$, Wenbo DONG ${ }^{1}$, , Jianhua $\mathrm{CHEN}^{2}$, Yuqiong $\mathrm{LI}^{2}$, Cuihua $\mathrm{ZHAO}^{3}$ \\ ${ }^{1}$ Department of Environmental Science and Engineering, Fudan University, Shanghai 200433, China \\ ${ }^{2}$ Guangxi Colleges and Universities Key Laboratory of Minerals Engineering, Guangxi University, Nanning 530004, China \\ ${ }^{3}$ College of Material Science and Engineering, Guangxi University, Nanning 530004, China
}

crossref http://dx.doi.org/10.5755/j01.ms.24.3.17855

Received 31 March 2017; accepted 30 September 2017

\begin{abstract}
The metal-support electronic interaction of dispersed $\mathrm{Pt}, \mathrm{Pd}$ and $\mathrm{Au}$ layers on $\gamma-\mathrm{Al}_{2} \mathrm{O}_{3}$ is studied by density functional theory (DFT) calculations. The results indicate that electrons transfer significantly between the contacting layers of $\mathrm{Au}, \mathrm{Pt}$ or $\mathrm{Pd}$ and the $\gamma-\mathrm{Al}_{2} \mathrm{O}_{3}$. Fukui function calculation results exhibit the electrophilicity of $\mathrm{Al}$ and $\mathrm{O}$ atoms on the Pt-supported surface is the greatest, while their nucleophilicity is the weakest. DOS calculation results demonstrate that the metal $\mathrm{d}$ orbital and $\mathrm{O} 2 \mathrm{p}$ orbital participate in the interactions, and the interaction between Pt $5 \mathrm{~d}$ orbital and O $2 \mathrm{p}$ orbital is the strongest.

Keywords: $\gamma$-alumina; noble metal layer; electronic interactions.
\end{abstract}

\section{INTRODUCTION}

$\gamma$-alumina $\left(\gamma-\mathrm{Al}_{2} \mathrm{O}_{3}\right)$ is commonly used as a support in catalysis due to its porousness, high dispersity and large specific surface area. $\gamma-\mathrm{Al}_{2} \mathrm{O}_{3}$ is an activated alumina and has many industrial applications. Transition metals, such as rhodium $(\mathrm{Rh})$, platinum $(\mathrm{Pt})$, and palladium $(\mathrm{Pd})$, can be finely dispersed on this type of ceramic porous support. Many efforts have been made to understand the catalytic activity, spectroscopic properties, and electronic properties of this type of catalyst [1-7].

The change of the electronic properties of metal particles after metal-support interaction is very critical for the catalytic activity of materials, and their influence on catalytic properties has garnered considerable attention. The occurrence of electronic effects between metal-support has been established [8-11]. Various interaction models have been proposed. Treesukol et al. found that the $\mathrm{Pt}$ atom interacts with a Bronsted proton and a nearby framework oxygen, and electrons transferred from the zeolite to the $\mathrm{Pt}$ atom, while the Bronsted proton withdrew excess electron density from the Pt atom, causing a zero net charge on the Pt atom [12]. Mallmann et al. [13, 14] proposed that electron transfer between the support oxygen atoms and the nearby metal particles. Using a combination of experimental measurements and theoretical DFT calculations, Mei et al [3] observed that pentacoordinated $\mathrm{Al}^{3+}$ sites on the $\gamma-\mathrm{Al}_{2} \mathrm{O}_{3}$ (100) surface can inhibit $\mathrm{Pt}$ sintering both thermodynamically and kinetically because of their strong interactions with atomic $\mathrm{Pt}$ or $\mathrm{Pt}$ oxide species. This suggests that the cations on the support may participate in the electronic transfer process. However, Mojet et al [15] proposed that the primary interaction is a Coulomb attraction between the metal particle and support oxygen ions, and this metal-support interaction model does not need electron transfer. These researchers suggested that the decrease in activity of metal clusters with increasing support alkalinity can be ascribed to a decrease in ionization potential of the metal particles directly induced by the Coulomb potential of the support.

The metal-support interaction is very important for the use of the catalyst because the desired catalytic reactivity of the supported metal can be obtained if the interaction is well-understood. However, the detailed charge transfer may not be detected by experimental technology due to the effects of the metal particle size and other difficult-tocontrol factors. Gao [16] has performed DFT calculations with the $\mathrm{Dmol}^{3}$ program on the single $\mathrm{Pt}, \mathrm{Pd}, \mathrm{Ag}, \mathrm{Sn}$ and $\mathrm{In}$ adsorption on the O-terminatedandAl-terminated $\gamma-\mathrm{Al}_{2} \mathrm{O}_{3}$ (110) surfaces and analysed the adsorption energy, atomic density of states and Mulliken charges. The present study focuses on the electronic interaction between metal layer $\left(\mathrm{Pt}, \mathrm{Au}\right.$ and $\mathrm{Pd}$ ) and $\gamma-\mathrm{Al}_{2} \mathrm{O}_{3}$ support using density functional theory. Based on the calculations, the detailed electronic transfer and interaction can be clearly shown. The results will help to characterize the nature of the metalsupport interaction.

\section{COMPUTATIONAL METHODS}

In this study, the properties of $\gamma-\mathrm{Al}_{2} \mathrm{O}_{3}$ coated with $\mathrm{Au}$, $\mathrm{Pt}$ and Pd metals were studied by density functional theory (DFT) calculations using CASTEP code with GGA-PW91 exchange-correlation potentials. The energy cut off is set to $400 \mathrm{eV}$ and SCF tolerance $1 \times 10^{-5} \mathrm{eV}$ atom ${ }^{-1}$. The surface of $\gamma-\mathrm{Al}_{2} \mathrm{O}_{3}$ (101) was cleaved from the optimized bulk state. Vaarkamp et al. have shown that the morphology of the $\mathrm{Pt}$ particles was similar to a Pt plane during high temperature reduction, and the $\mathrm{Pt}-\mathrm{O}$ distance was $2.2 \AA$ on the metalsupport interface [1]. In our study, the metal layer and $\gamma-$ $\mathrm{Al}_{2} \mathrm{O}_{3}$ layer were built together with a small interval (approximately $2.2 \AA$ ) between these two layers, as shown in Fig. 1. In order to eliminate the mirror effect, a vacuum

\footnotetext{
${ }^{*}$ Corresponding author. Tel.: +86-771-3232200; fax: +86-771-3233566.

E-mail address: $346276482 @ q q . c o m$ (W.B. Dong)
} 
layer was placed at the other end in contrast to the metal $/ \gamma$ $\mathrm{Al}_{2} \mathrm{O}_{3}$ contact end.

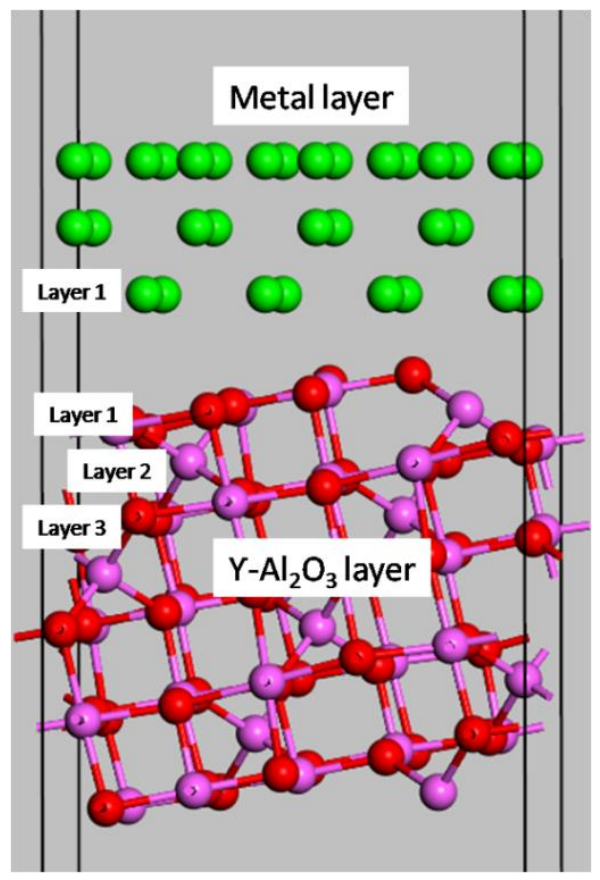

Fig. 1. Calculated model of $\gamma-\mathrm{Al}_{2} \mathrm{O}_{3}$ surface supported metals. The atoms lying on the same plane is labelled as layer 1, layer 2 or layer 3

\section{RESULTS AND DISCUSSION}

\subsection{Charge transfer between metal $/ \gamma-\mathrm{Al}_{2} \mathrm{O}_{3}$ interface}

The Mulliken charge population of the three layers of $\mathrm{Al}$ and $\mathrm{O}$ atoms contacting with metals were calculated, and the charges of $\mathrm{Al}$ or $\mathrm{O}$ atoms on the same layer were added. The results are shown in Table 1.

It is shown that the charges of $\mathrm{Al}$ or $\mathrm{O}$ atoms on layer 1 change significantly after contacting with metals, whereas charges on layer 2 and layer 3 have not changed much. This indicates that $\mathrm{Au}, \mathrm{Pt}$ and $\mathrm{Pd}$ metals have great influence on the charge states of the outer surface atoms of $\gamma-\mathrm{Al}_{2} \mathrm{O}_{3}$.

On pure surface, the positive charges of $\mathrm{Al}$ atoms are less than the negative charges of $\mathrm{O}$ atoms, resulting in the negatively charged outer surface. The positive charge of $\mathrm{Al}$ atoms and negative charge of $\mathrm{O}$ atoms on the $\gamma-\mathrm{Al}_{2} \mathrm{O}_{3}$ supported $\mathrm{Au}, \mathrm{Pt}$ and $\mathrm{Pd}$ metals decrease compared with that on pure $\gamma-\mathrm{Al}_{2} \mathrm{O}_{3}$. However, the decrease of positive charge of $\mathrm{Al}$ atoms is more than the negative charge of $\mathrm{O}$ atoms, resulting in the increase of the negative charge of the outer surface. The above results suggest that the interfacial Al takes part in the interaction of metal with support, which is consistent with the study by Mojet et al. [15].
Electron loss of $\mathrm{Au}, \mathrm{Pt}$ or $\mathrm{Pd}$ to the surface was observed. We calculated the total charges of metals on metal layer 1. It is observed that the Pt on metal layer 1 loses the most electrons to the surface, i.e., the Pt atoms on layer 1 have the most positive charges $(+1.94$ e) followed by $\mathrm{Pd}$ (+1.09 e) and $\mathrm{Au}(+0.55 \mathrm{e})$. This finding suggests that the electronic interaction of $\mathrm{Pt}$ metal with the $\gamma-\mathrm{Al}_{2} \mathrm{O}_{3}$ surface is the greatest after contact with the surface. It is noted that the outer electronic structures of $\mathrm{Au}, \mathrm{Pt}$ and $\mathrm{Pd}$ are $5 \mathrm{~d}^{10} 6 \mathrm{~s}^{1}$, $5 \mathrm{~d}^{9} 6 \mathrm{~s}^{1}$ and $4 \mathrm{~d}^{10}$, respectively. The Pt $5 \mathrm{~d}$ orbital is not fully filled, while $\mathrm{Au} 4 \mathrm{~d}$ and $\mathrm{Pd} 5 \mathrm{~d}$ orbitals are fully filled. This finding causes the stronger activity of Pt $5 \mathrm{~d}$ orbital than either $\mathrm{Au} 4 \mathrm{~d}$ or Pd 5d orbitals, and consequently, Pt loses more electrons. In addition, Pd atom has an outer orbital of $6 \mathrm{~s}^{1}$, while Au does not have an unfilled s orbital; hence, Pd loses more electrons than Au.

\subsection{Electrophilicity and nucleophilicity of surface atoms}

It is known that frontier molecular orbital theory (FMO) can be used to predict the chemical reactivity of molecules. Fukui functions $(f(r))$ are the analogue of frontier orbitals, both of which are important reactivity criteria [17-20]. The function $f$ has different values at different points in the species. It is assumed that the preferred direction is the one with largest $f(r)$ at the reaction site. Two Fukui indices, $f^{+}(r)$ and $f(r)$, control the nucleophilic attack and electrophilic attack, respectively. The $f^{+}(r)$ and $f^{-}(r)$ are the electrophilic value and nucleophilic value of the $\mathrm{r}$ atom, respectively, and the Fukui indices were calculated by Eq. 1 and Eq. 2:

$$
\begin{aligned}
& f^{+}(r)=\frac{1}{\Delta N}\left(\rho_{N+\Delta}(r)-\rho_{N}(r)\right) ; \\
& f^{-}(r)=\frac{1}{\Delta N}\left(\rho_{N}(r)-\rho_{N-\Delta}(r)\right),
\end{aligned}
$$

where the $\rho(r)$ means the charge density of $r$ atom. The $r$ means the atom which was calculated. Moreover, the larger the $f^{+}(r)$ value, the more susceptible to nucleophilic attack. Similarly, the larger the $f^{-}(r)$ value, the more susceptible to electrophilic attack.

We calculated the $f^{+}(r)$ and $f(r)$ values of surface $\mathrm{Al}$ and $\mathrm{O}$ atoms, as shown in Table 2. It is found that the $\mathrm{Al}$ atom on the $\gamma-\mathrm{Al}_{2} \mathrm{O}_{3}$ surface supported Pt has the largest $f^{+}(r)$ value followed by that on the surface supported $\mathrm{Au}$ and, next, that on the surface supported $\mathrm{Pd}$. The $f^{+}(r)$ value of $\mathrm{O}$ atoms has the same order as $\mathrm{Al}$ atom on these three supported metal surfaces. For the $f(r)$ index, the $\mathrm{Al}$ atom on the surface supported $\mathrm{Au}$ is the largest followed by that the surface supported Pd and, next, that on the surface supported Pt. The $f(r)$ index of $\mathrm{O}$ atom is notably small.

There results suggest that the electrophilicity of $\mathrm{Al}$ and $\mathrm{O}$ atoms on the surface supported $\mathrm{Pt}$ is the greatest, while their nucleophilicity is the weakest.

Table 1. Total charges of the three layers atoms contacting with metals (in e)

\begin{tabular}{|c|c|c|c|c|c|}
\hline & $\mathrm{Al}$ atoms of layer 1 & $\mathrm{O}$ atoms of layer 1 & $\mathrm{Al}$ atoms of layer 2 & $\mathrm{Al}$ atoms of layer 3 & $\mathrm{O}$ atoms of layer 3 \\
\hline $\mathrm{Pure} \gamma-\mathrm{Al}_{2} \mathrm{O}_{3}$ & +4.80 & -6.62 & +3.56 & +7.95 & -11.97 \\
\hline $\mathrm{Au} / \gamma-\mathrm{Al}_{2} \mathrm{O}_{3}$ & +3.49 & -5.59 & +3.33 & +7.90 & -11.68 \\
\hline $\mathrm{Pt} / \gamma-\mathrm{Al}_{2} \mathrm{O}_{3}$ & +3.40 & -5.39 & +3.31 & +7.85 & -11.69 \\
\hline $\mathrm{Pd} / \gamma-\mathrm{Al}_{2} \mathrm{O}_{3}$ & +3.40 & -5.57 & +3.26 & +7.77 & -11.74 \\
\hline
\end{tabular}


Table 2. Fukui indices of surface atoms

\begin{tabular}{|c|c|c|c|c|}
\hline & \multicolumn{2}{|c|}{$\mathrm{Al}$} & \multicolumn{2}{c|}{ O } \\
\cline { 2 - 5 } & $f^{+}(r)$ & $f(r)$ & $f^{+}(r)$ & $f(r)$ \\
\hline $\mathrm{Au} / \gamma-\mathrm{Al}_{2} \mathrm{O}_{3}$ & 0.013 & 0.012 & 0.005 & 0.004 \\
\hline $\mathrm{Pt} / \gamma-\mathrm{Al}_{2} \mathrm{O}_{3}$ & 0.018 & 0.006 & 0.011 & 0 \\
\hline $\mathrm{Pd} / \gamma-\mathrm{Al}_{2} \mathrm{O}_{3}$ & 0.011 & 0.010 & 0.004 & 0.004 \\
\hline
\end{tabular}

In addition, it is clearly observed from the specified $f^{+}(r)$ and $f(r)$ values that the nucleophilicity and electrophilicity of $\mathrm{Al}$ and $\mathrm{O}$ atoms on the surfaces supported $\mathrm{Au}$ and $\mathrm{Pd}$ are close.

Based on the above results, it can be predicted that the Pt-supported $\gamma-\mathrm{Al}_{2} \mathrm{O}_{3}$ surface is the most susceptible to nucleophilic attack. In other words, the electrophilicity of $\gamma-\mathrm{Al}_{2} \mathrm{O}_{3}$ surface supported $\mathrm{Pt}$ is the greatest. Hence, the Ptsupported $\gamma-\mathrm{Al}_{2} \mathrm{O}_{3}$ may have a better performance of oxidation of organic matters than $\mathrm{Au}$ - and $\mathrm{Pd}$ - supported $\gamma-\mathrm{Al}_{2} \mathrm{O}_{3}$.

\subsection{DOS of surface atoms}

Density of states (DOS) can give clear orbital interactions between atoms and the internal orbital interactions of an atom. Fig. 2 -Fig. 4 show the densities of states (DOSs) of Al, O, and metal atoms, respectively. The Fermi level $\left(E_{\mathrm{F}}\right)$ is set at zero energy.
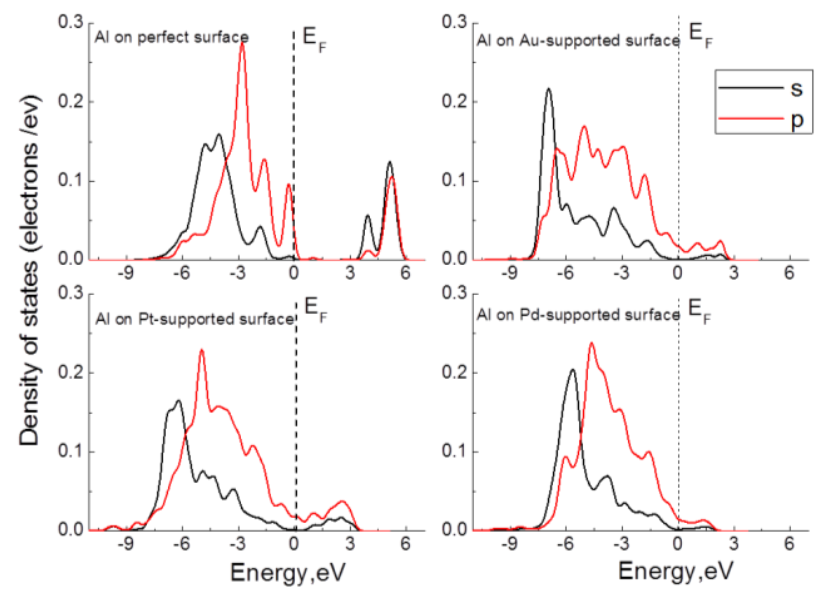

Fig. 2. DOS of Al atoms on pure and metal-coated surfaces
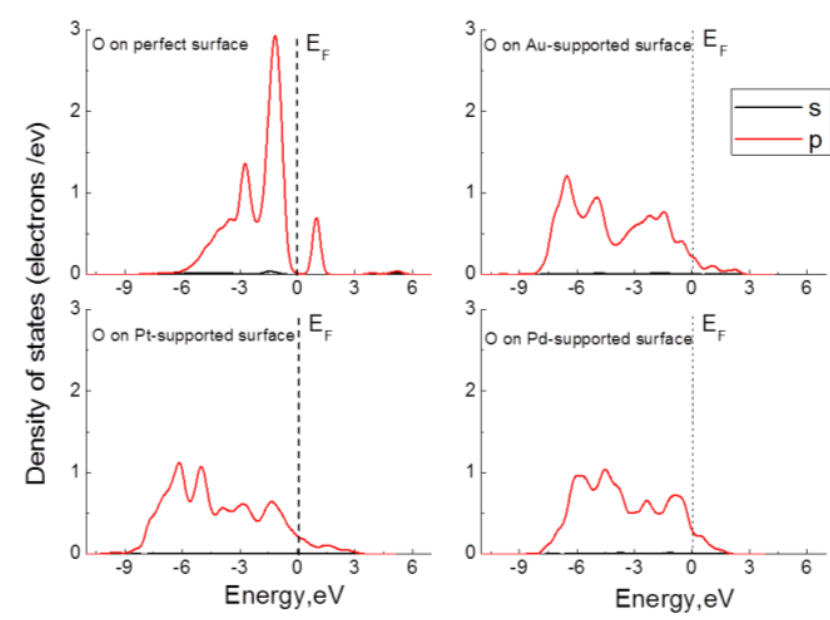

Fig. 3. DOS of $\mathrm{O}$ atoms on pure and metal-coated surfaces

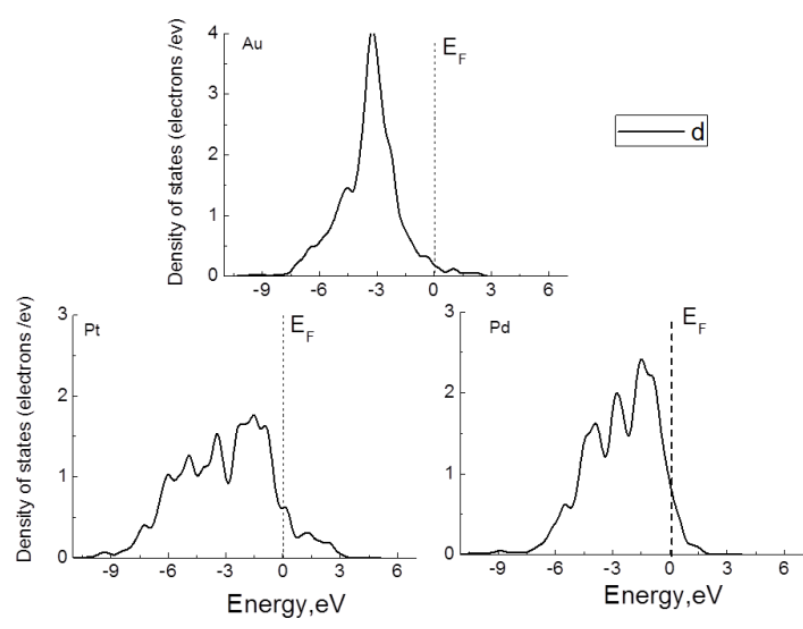

Fig. 4. DOS of metal atoms

It is shown that on pure surface, the valence bands and conduction bands of $\mathrm{Al}$ and $\mathrm{O}$ atoms are discrete on the two sides of Fermi level. The valence band and conduction band of $\mathrm{Al}$ is consisted with $3 \mathrm{~s}$ and $3 \mathrm{p}$ states, and $2 \mathrm{p}$ is the main contributor to the DOS of $\mathrm{O}$ atom. Although metal interacts with the surface $\mathrm{O}$ atom, the DOS of surface $\mathrm{Al}$ atom is also significantly influenced. It is found that the $3 p$ orbital of $\mathrm{Al}$ atom is continuously connected together across the Fermi level. This situation also occurred for $\mathrm{O} 2 \mathrm{p}$ orbital but not for $\mathrm{Al} 3 \mathrm{~s}$ orbital. This suggests that the electronic activity of $\mathrm{Al} 3 \mathrm{p}$ and $\mathrm{O} 2 \mathrm{p}$ orbitals is enhanced due to the presence of metals.

The d orbital of metal is involved in the reaction with $\mathrm{O}$ $\mathrm{p}$ orbital. It is found that the interaction range between $\mathrm{O} 2 \mathrm{p}$ and $\mathrm{Pt} d$ states are the widest (from -9 to $3 \mathrm{eV}$ ). In addition, the width of $\mathrm{Al} \mathrm{3p}$ orbital on Pt-supported surface are also the largest ( -10 to $3.5 \mathrm{eV}$ ). These results suggest that $\mathrm{Al} 3 \mathrm{p}$ and $\mathrm{O} 2 \mathrm{p}$ electrons on Pt-supported surface have the largest activity compared to the other two metal-supported surfaces This finding indicates that the Pt-supported $\gamma-\mathrm{Al}_{2} \mathrm{O}_{3}$ surface is the most susceptible to nucleophilic attack.

\section{CONCLUSIONS}

Our theoretical calculations confirm the electronic transfer between $\mathrm{Au}, \mathrm{Pt}$ or $\mathrm{Pd}$ and the $\gamma-\mathrm{Al}_{2} \mathrm{O}_{3}$ interface. Strong electronic interactions occur at the contacting layers of metal and $\gamma-\mathrm{Al}_{2} \mathrm{O}_{3}$ support. It is observed that $\mathrm{Al}$ atom obtained electrons after the interaction of metal and $\mathrm{O}$ atom, while the metal atom and $\mathrm{O}$ atom lost electrons. As per the role of metals, the electrophilicity and nucleophilicity of interfacial $\mathrm{Al}$ and $\mathrm{O}$ atoms are changed. The electrophilicity of $\mathrm{Al}$ and $\mathrm{O}$ atoms on the Pt-supported surface is the greatest, while their nucleophilicity is the weakest. Furthermore, the nucleophilicity and electrophilicity of $\mathrm{Al}$ and $\mathrm{O}$ atoms on the surfaces supported $\mathrm{Au}$ and $\mathrm{Pd}$ are close. Through the calculated results, it is determined that the Pt- 
supported $\gamma-\mathrm{Al}_{2} \mathrm{O}_{3}$ is the most susceptible to nucleophilic attack, which may have a better performance of oxidation on organic matters in comparison to $\mathrm{Au}$ - or $\mathrm{Pd}$ - supported $\gamma$ $\mathrm{Al}_{2} \mathrm{O}_{3}$.

It is found the metal $d$ orbital and $O 2 p$ orbital participate in the interactions. Moreover, the interaction between Pt $5 \mathrm{~d}$ orbital and $\mathrm{O} 2 \mathrm{p}$ orbital is the strongest. The electronic structure of $\mathrm{Al} 3 \mathrm{p}$ is also significantly changed.

Only the interface interaction of metal-support was considered in the present study; however, as noted in the introduction, the metal particle size, as well as other difficult-to-control factors, may have great effects on the electronic state of the particle. These aspects warrant further investigation using theoretical calculation methods in future research.

\section{Acknowledgments}

The authors would like to acknowledge financial support provided by Guangxi Natural Science Foundation (No. 2014GXNSFAA118342).

\section{REFERENCES}

1. Vaarkamp, M.,

Miller, J.T.,

Modica, F.S.,

Koningsberger, D.C. On the Relation Between Particle Morphology, Structure of the Metal-Support Interface, And Catalytic Properties of $\mathrm{Pt} / \gamma-\mathrm{Al}_{2} \mathrm{O}_{3}$ Journal of Catalysis 163 (2) 1996: pp. 294-305.

https://doi.org/10.1006/jcat.1996.0330

2. Srinivasan, A., Depcik, C. Review of Chemical Reactions in the NO Reduction By CO on Rhodium/Alumina Catalysts Catalysis Reviews: Science and Engineering 52 (4) 2010: pp. $462-493$. https://doi.org/10.1080/01614940.2010.522485

3. Mei, D.H., Kwak, J.H., Hu, J.Z., Cho, S.J., Szanyi, J., Allard, L.F., Peden, C.H.F. Unique Role of Anchoring Penta-coordinated $\mathrm{Al}^{3+}$ Sites in the Sintering of $\gamma-\mathrm{Al}_{2} \mathrm{O}_{3}-$ Supported Pt Catalysts Journal of Physical Chemistry Letters 1 (18) 2010: pp. 2688-2691. https://doi.org/10.1021/jz101073p

4. Koningsberger, D.C., Vaarkamp, M. Influence of the Reduction Temperature on the Structure of the Metal Particles and the Metal-Support Interface of $\mathrm{Pt} / \Gamma-\mathrm{Al}_{2} \mathrm{O}_{3}$ Catalysts Physica B Condensed Matter 208-209 1995: pp. 633-636. https://doi.org/10.1016/0921-4526(94)00776-R

5. Roscioni, O.M., Dyke, J.M. Structural Characterization of Supported $\mathrm{RhI}(\mathrm{CO})_{2} / \gamma-\mathrm{Al}_{2} \mathrm{O}_{3}$ Catalysts by Periodic DFT Calculations Journal of Physical Chemistry C 117 (38) 2013: pp. $19464-19470$.

https://doi.org/10.1021/jp405549k

6. Alexeev, O.S., Panjabi, G., Phillips, B.L., Gates, B.C. Carbonylation and Decarbonylation of $\gamma-\mathrm{Al}_{2} \mathrm{O}_{3}-\mathrm{Supported}$ Hexarhodium Clusters: Characterization by Infrared, ${ }^{13} \mathrm{C}$ NMR, and Extended X-ray Absorption Fine Structure Spectroscopies Langmuir 19 (22) 2003: pp. 9494-9503. https://doi.org/10.1021/la0348970

7. Fung, A.S., Kelley, M.J., Koningsberger, D.C., Gates, B.C. $\quad \gamma-\mathrm{Al}_{2} \mathrm{O}_{3}$-Supported Re-Pt Cluster Catalyst Prepared from $\left[\mathrm{Re}_{2} \mathrm{Pt}(\mathrm{CO})_{12}\right]$ : Characterization by Extended $\mathrm{X}$-ray Absorption Fine Structure Spectroscopy and Catalysis of Methylcyclohexane Dehydrogenation Journal of the American Chemical Society $119(25)$ 1997: pp. $5877-5887$. https://doi.org/10.1021/ja962816z

8. Gallezot, $\mathbf{P}$. The State and Catalytic Properties of Platinum and Palladium in Faujasite-Type Zeolites Catalysis ReviewsScience and Engineering 20 1979: pp. 121-154. https://doi.org/10.1080/03602457908065108

9. Gallezot, P., Weber, R., Betta, R.A.D., Boudart, M. Cheminform Abstract: Investigation by X-ray Absorption Spectroscopy of Platinum Clusters Supported on Zeolites Chemischer Informationsdienst 34 (14) 1979: pp. 40-42. https://doi.org/10.1515/zna-1979-0107

10. Besoukhanova, C., Guidot, J., Barthomeuf, D. Platinumzeolite Interactions in Alkaline L Zeolites. Correlations between Catalytic Activity and Platinum State Journal of Chemical Society-Faraday Transactions 77 1981: pp. $1595-1604$.

11. Larsen, G., Haller, G.L. Metal-support Effects in Pt/L-zeolite Catalysts Catalysis Letters $3(1)$ 1989: pp. $103-110$. https://doi.org/10.1007/BF00765061

12. Treesukol, P., Srisuk, K., Limtraku, J., Truong, T.N. Nature of the Metal-support Interaction in Bifunctional Catalytic Pt/H-ZSM-5 Zeolite Journal of Physical Chemistry B 109 (24) 2005: pp. 11940 - 11945. https://doi.org/10.1021/jp0511348

13. Mallmann, A.D., Barthomeuf, D. Correlation between Benzene Hydrogenation Activity and Zeolite Basicity in Ptfaujasites Journal de Chimie Physique et de Physico-Chimie Biologique 87 (4) 1990: pp. 535-538.

14. Mallmann, A.D., Barthomeuf, D. Specific Platinum Particles Properties in Basic Zeolites Studies in Surface Science and Catalysis 46 1989: pp. 429-438. https://doi.org/10.1016/S0167-2991(08)60999-4

15. Mojet, B.L., $\quad$ Miller, J.T., $\quad$ Ramaker, D.E., Koningsberger, D.C. A New Model Describing the Metalsupport Interaction in Noble Metal Catalysts Journal of Catalysis $186(2)$ 1999: 373-386. https://doi.org/10.1006/jcat.1999.2568

16. Gao, H.W. DFT Study of the Absorption Properties of Single $\mathrm{Pt}, \mathrm{Pd}, \mathrm{Ag}$, In and $\mathrm{Sn}$ on the $\gamma-\mathrm{Al}_{2} \mathrm{O}_{3}(110)$ Surface Chemical Physics Letters 657 2016: pp. 11-17. https://doi.org/10.1016/j.cplett.2016.05.056

17. Parr, R.G., Yang, W. Density Functional Approach to the Frontier-electron Theory of Chemical Reactivity Journal of the American Chemical Society $106(14)$ 1984: pp. $4049-4050$. https://doi.org/10.1021/ja00326a036

18. Ayers, P.W., Levy, M. Perspective on "Density functional Approach to the Frontier-electron Theory of Chemical Reactivity" Theoretical Chemistry Accounts 103 (3) 2000: pp. $353-360$. https://doi.org/10.1007/s002149900093

19. Geerlings, P., Proft, F.D., Langenaeker, W. Conceptual Density Functional Theory Chemical Reviews 103 2003: pp $1793-1873$. https://doi.org/10.1021/cr990029p

20. Pintér, B., Proft, F.D., Speybroeck, V.V., Hemelsoet, K., Waroquier, M., Chamorro, E., $\quad$ Veszprémi, T., Geerlings, P. Spin-Polarized Conceptual Density Functional Theory Study of the Regioselectivity in Ring Closures of Radicals Journal of Organic Chemistry 72 2007: pp. $348-356$ https://doi.org/10.1021/jo0613885 